\title{
Quality Evaluation of the Weekly Vertical Loading Effects Induced from Continental Water Storage Models
}

\author{
Z. Li, T. van Dam, X. Collilieux, Z. Altamimi, P. Rebischung, and S. Nahmani
}

\begin{abstract}
To remove continental water storage (CWS) signals from the GPS data, CWS mass models are needed to obtain predicted surface displacements. We compared weekly GPS height time series with five CWS models: (1) the monthly and (2) three-hourly Global Land Data Assimilation System (GLDAS); (3) the monthly and (4) one-hourly ModernEra Retrospective Analysis for Research and Applications (MERRA); (5) the six-hourly National Centers for Environmental Prediction-Department of Energy (NCEP-DOE) global reanalysis products (NCEP-R-2). We find that of the 344 selected global IGS stations, more than $77 \%$ of stations have their weighted root mean square (WRMS) reduced in the weekly GPS height by using both the GLDAS and MERRA CWS products to model the surface displacement, and the best improvement concentrate mainly in North America and Eurasia. We find that the one-hourly MERRA-Land dataset is the most appropriate product for modeling weekly vertical surface displacement caused by CWS variations. The threehourly GLDAS data ranks the second, while the GLDAS and MERRA monthly products rank the third. The higher spatial resolution MERRA product improves the performance of the CWS model in reducing the scatter of the GPS height by about 2-6\% compared with the GLDAS. Under the same spatial resolution, the higher temporal resolution could also improve the performance by almost the same magnitude. We also confirm that removing the ATML and NTOL effects from the weekly GPS height would remarkably improve the performance of CWS model in correcting the GPS height by at least $10 \%$, especially for coastal and island stations. Since the GLDAS product has a much greater latency than the MERRA product, MERRA would be a better choice to model surface displacements from CWS. Finally, we find that the NCEP-R-2 data is not sufficiently precise to be used for this application. Further work is still required to determine the reason.
\end{abstract}

\section{Keywords}

Continental water storage $\bullet$ GLDAS $\bullet$ GPS height $\bullet$ MERRA $\bullet$ NCEP

Z. Li $(\bowtie) \cdot$ T. van Dam

Faculté des Science, de la Technologie et de la Communication, University of Luxembourg, 6 rue Richard Coudenhove-Kalergi L-1359, Luxembourg, Luxembourg e-mail: zhao.li@uni.lu

X. Collilieux $\bullet$ Z. Altamimi $\bullet$ P. Rebischung $\bullet$ S. Nahmani IGN/LAREG and GRGS, Univ Paris Diderot, Sorbonne Paris Cité, Paris, France

\section{$1 \quad$ Introduction}

Previous research has confirmed the strong correlation between Continental Water Storage (CWS) induced vertical surface displacement and the global positioning system (GPS) height time series (van Dam et al. 2001, 2007; Tregoning et al. 2009; Fritsche et al. 2012). This environmentally driven displacement adds noise to the 
GPS data being used for geodynamic investigations, such as postglacial rebound, sea level rise, etc. To remove this environmental signal from the GPS data, the CWS mass models are required to predict surface displacements. However, these CWS model induced vertical surface displacement are often not consistent with one another and with the seasonal changes in the position of the GPS markers (Jiang et al. 2013).

Currently, the most frequent used CWS mass models are the soil moisture (SM) plus snow water equivalent (SWE) from the monthly Global Land Data Assimilation System (GLDAS) $^{1}$ (Rui 2011) and the six-hourly National Centers for Environmental Prediction-National Center for Atmospheric Research (NCEP-NCAR) global reanalysis datasets (R-1) (Kalnay et al. 1996), with spatial resolutions as $1^{\circ} \times 1^{\circ}$ and $1.875^{\circ} \times(1.8889-1.9048)^{\circ}$ respectively. It is well known that the CWS model in the R-1 are inaccurate (Kanamitsu et al. 2002), and (Jiang et al. 2013) found that the vertical loading time series from the R-1 CWS model were not fit well with the GPS height. To fix the known errors and also update the parameterizations of physical processes in R-1, the NCEP-Department of Energy (NCEP-DOE) global reanalysis products (NCEP-R-2) came into being ${ }^{2}$ (Kanamitsu et al. 2002). Are the temporal or spatial resolutions of the CWS model from the GLDAS and the NCEP-R-2 sufficient for correcting the GPS height time series?

Since 2012, the Modern-Era Retrospective Analysis for Research and Applications (MERRA) published an improved land surface data product called MERRA-Land reanalysis $^{3}$ (Reichle et al. 2011; Reichle 2012). It provides both monthly and one-hourly CWS estimates for snow mass (SNOMAS) and SM with spatial resolution as $1^{\circ} / 2^{\circ} \times 2^{\circ} / 3^{\circ}$ in latitude and longitude. In addition, GLDAS also provides three-hourly CWS estimates. Whether these higher temporal and spatial resolution products would improve the correlation between the CWS driven displacement and the GPS height is the motivation for this research.

In this paper, we assess the quality of five CWS mass model induced vertical surface displacements, that is the CWS estimates from the monthly and three-hourly GLDAS, monthly and hourly MERRA-Land, together with the sixhourly NCEP-R-2 products, by inter-comparing similar models with each other and with the latest International GNSS service (IGS; Dow et al. 2009) combined weekly GPS coordinate time series. We test whether higher spatial or temporal resolution CWS products are better at reducing the scatter in the GPS height.

\footnotetext{
${ }^{1}$ http://disc.sci.gsfc.nasa.gov/services/grads-gds/gldas.

${ }^{2} \mathrm{http} / / / \mathrm{www}$. esrl.noaa.gov/psd/data/gridded/data.ncep.reanalysis2. html.

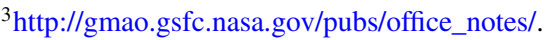

\section{$2 \quad$ Data Processing}

\subsection{Farrell's Green's Function Approach}

The predicted vertical displacement of a point on the Earth's surface driven by changes in CWS can be determined by convolving Farrell's Green's functions (Farrell 1972) with a surface mass model over the surface of the Earth (van Dam and Wahr 1987). The basic equation can be written as:

$$
d_{u}(\theta, \phi)=\sum_{i=1}^{n l o n} \sum_{j=1}^{\text {nlat }} \triangle P_{i, j} G_{i, j}^{u} A_{i, j}
$$

where $i$ and $j$ denote a unique loading grid point from given CWS model, nlon and nlat represent the number of CWS grid unit increment in longitude and latitude respectively, and $G_{i, j}^{u}$ denotes the Green's function for the vertical component of surface displacement. $\triangle P_{i, j}$ is the CWS variation at the grid point and $A_{i, j}$ is the area of the loading grid point. Here we choose the Green's function derived in the center of figure (CF) frame to maintain consistency between the predicted loading and GPS heights (Dong et al. 1997; Blewitt 2003).

\subsection{Data Description}

Here, we model the vertical surface displacements for 344 global IGS stations using the above five different CWS models. The time period we consider runs from January 01, 2000 to December 31, 2010. For both GLDAS monthly and three-hourly products, we use the one degree Noah-Version 1 SM and SWE data. ${ }^{4}$ We did not include the SWE data above the latitude of $60.5 \mathrm{~N}$. This area includes Greenland and most Arctic regions; GLDAS does not model snow dynamics well in these regions (Rui 2011; Jiang et al. 2013).

For the monthly and hourly MERRA-Land products, we use the variables called the total profile soil moisture content (PRMC) and the SNOMAS, which represent the SM and SWE respectively (tavg1_2d_mld_Nx ${ }^{5}$ ). To convert PRMC into equivalent water height, a corresponding constant file that describes the thickness of the soil layer is also needed (const_2d_mld_Nx ${ }^{6}$ ).

The last CWS model we use is the volumetric soil moisture (VSM) and the water equivalent of accumulated snow

\footnotetext{
${ }^{4} \mathrm{ftp} / / /$ hydro1.sci.gsfc.nasa.gov/data/s4pa/GLDAS_V1.

${ }^{5}$ http://disc.sci.gsfc.nasa.gov/daac-bin/DataHoldings.pl? LOOKUPID_List=MST1NXMLD.

${ }^{6}$ http://disc.sci.gsfc.nasa.gov/daac-bin/DataHoldings.pl? LOOKUPID_List=MSCONXMLD.
} 
Table 1 Details of the five CWS models used

\begin{tabular}{|c|c|c|c|c|c|}
\hline Model & Data source & Unit & Temporal resolution & Spatial resolution (degree) & Latency \\
\hline \multirow[t]{2}{*}{ GLDAS-A (NOAH) } & SM (4 layers) & $\mathrm{kg} / \mathrm{m}^{2}$ & \multirow[t]{2}{*}{ Monthly } & \multirow[t]{2}{*}{$1 \times 1$} & \multirow[t]{2}{*}{$1-4$ months } \\
\hline & SWE & $\mathrm{kg} / \mathrm{m}^{2}$ & & & \\
\hline \multirow[t]{2}{*}{ NCEP-R-2 } & SM (2 layers) & $\mathrm{m}^{3} / \mathrm{m}^{3}$ & \multirow[t]{2}{*}{ 6-hourly } & \multirow[t]{2}{*}{$1.875 \times(1.8889-1.9048)$} & \multirow[t]{2}{*}{ 3-4 days } \\
\hline & SWE & $\mathrm{kg} / \mathrm{m}^{2}$ & & & \\
\hline \multirow[t]{2}{*}{ GLDAS-B (NOAH) } & SM (4 layers) & $\mathrm{kg} / \mathrm{m}^{2}$ & \multirow[t]{2}{*}{ 3-hourly } & \multirow[t]{2}{*}{$1 \times 1$} & \multirow[t]{2}{*}{$1-4$ months } \\
\hline & SWE & $\mathrm{kg} / \mathrm{m}^{2}$ & & & \\
\hline \multirow[t]{2}{*}{ MERRA-A } & PRMC & $\mathrm{m}^{3} / \mathrm{m}^{3}$ & \multirow[t]{2}{*}{ Monthly } & \multirow[t]{2}{*}{$2 / 3 \times 1 / 2$} & \multirow[t]{2}{*}{$1-2$ months } \\
\hline & SNOMAS & $\mathrm{kg} / \mathrm{m}^{2}$ & & & \\
\hline \multirow[t]{2}{*}{ MERRA-B } & PRMC & $\mathrm{m}^{3} / \mathrm{m}^{3}$ & \multirow[t]{2}{*}{ 1-hourly } & \multirow[t]{2}{*}{$2 / 3 \times 1 / 2$} & \multirow[t]{2}{*}{$1-2$ months } \\
\hline & SNOMAS & $\mathrm{kg} / \mathrm{m}^{2}$ & & & \\
\hline
\end{tabular}

depth (SD) from the NCEP-R-2 products. $^{7}$ Table 1 shows the details of each CWS model. Note that the groundwater component are excluded from all the five CWS models (Rui 2011; Reichle 2012; Kanamitsu et al. 2002), and all the five CWS models use the soil moisture and the snow water equivalence as the input for calculating the CWS loading time series, although the name of the variables are different from model to model. This condition makes our results more comparable to each other.

For comparison, the latest IGS combined weekly GPS coordinate time series until the year 2011 is applied to evaluate the performance of each CWS model in correcting the GPS height. These data include homogeneously reprocessed coordinates from the first IGS reprocessing campaign (Chen et al. 2013). The reprocessed individual solutions from each IGS analysis center (AC) are then recombined using the combination strategy of the new IGS combination center (Rebischung et al. 2012). Compared with previous products, the advantage of this IGS combined solution is that it implements the absolute antenna calibrations for both satellites and receivers. However, it still has some limitations, for example, the higher-order ionospheric delay together with the diurnal and semi-diurnal atmospheric tides are not considered during the data processing. ${ }^{8}$

Because the applied GPS weekly height time series include the surface displacement caused by atmospheric tides, together with the impacts of non-tidal ocean loading (NTOL) and atmospheric loading (ATML) effects, here we also model stations' displacement induced by atmospheric and oceanic loading effects using Farrell's Green's function approach, to investigate whether the comparison between CWS loading and GPS height would be changed or not if these two kinds of loading effects are removed from the GPS observations first. The MERRA provided global 6-hourly

\footnotetext{
${ }^{7}$ http://www.esrl.noaa.gov/psd/cgi-bin/db_search/SearchMenus.pl? Dataset=NCEP/DOE+AMIP-II+Reanalysis+(Reanalysis- 2$) \&$ group=1 . ${ }^{8}$ http://acc.igs.org/reprocess.html.
}

surface pressure grid $^{9}$ is used for modeling the ATML, while the 12-hourly ocean bottom pressure (OBP) from the estimating the circulation and climate of the ocean (ECCO) global model from the JPL kf080 analysis ${ }^{10}$ is used for modeling the NTOL. The spatial resolution for these two selected products are at $1^{\circ} / 2^{\circ} \times 2^{\circ} / 3^{\circ}$ and $(1-0.3)^{\circ} \times 1^{\circ}$ in latitude and longitude respectively.

During the loading calculation, we firstly remove a 10year mean of the total CWS from 2000 to 2009 for each CWS model. Then, the residual CWS is convolved with the Farrell's Green's function to obtain the vertical surface displacement. The data are then detrended, averaged or interpolated into daily solutions corresponding to decimal year, or weekly solutions corresponding to the GPS week. For the ATML and NTOL, we follow the same procedure as the CWS loading calculation except that there is no need to remove the linear trend in the obtained ATML time series. Note that we assume that the total mass of the atmosphere, continental water together with ocean is constant, and simply sum up individual loading effects to obtain a stations displacement caused by total loads (Jiang et al. 2013). The gravitational consistency and mass conservation on surface loads are not considered here (Clarke et al. 2005). We state that this is a limitation of this investigation.

Before comparison with the detrended loading results, offsets in both the weekly GPS height time series should be carefully detected and removed. Then a linear trend should also be removed from the GPS observations. When implementing the comparison, we interpolate (for monthly products) or average (for subdaily products) the loading corrections for each station into each epoch of the GPS weekly time series to obtain load-corrected GPS data (Jiang et al. 2013). The red dots in Fig. 1 show the spatial distribution of the 344 stations used (Wessel and Smith 2013).

\footnotetext{
${ }^{9}$ http://disc.sci.gsfc.nasa.gov/daac-bin/FTPSubset.pl? LOOKUPID_List=MAI6NVANA.

${ }^{10} \mathrm{http} / / /$ ecco.jpl.nasa.gov/thredds/catalog/las/kf080/catalog.html.
} 


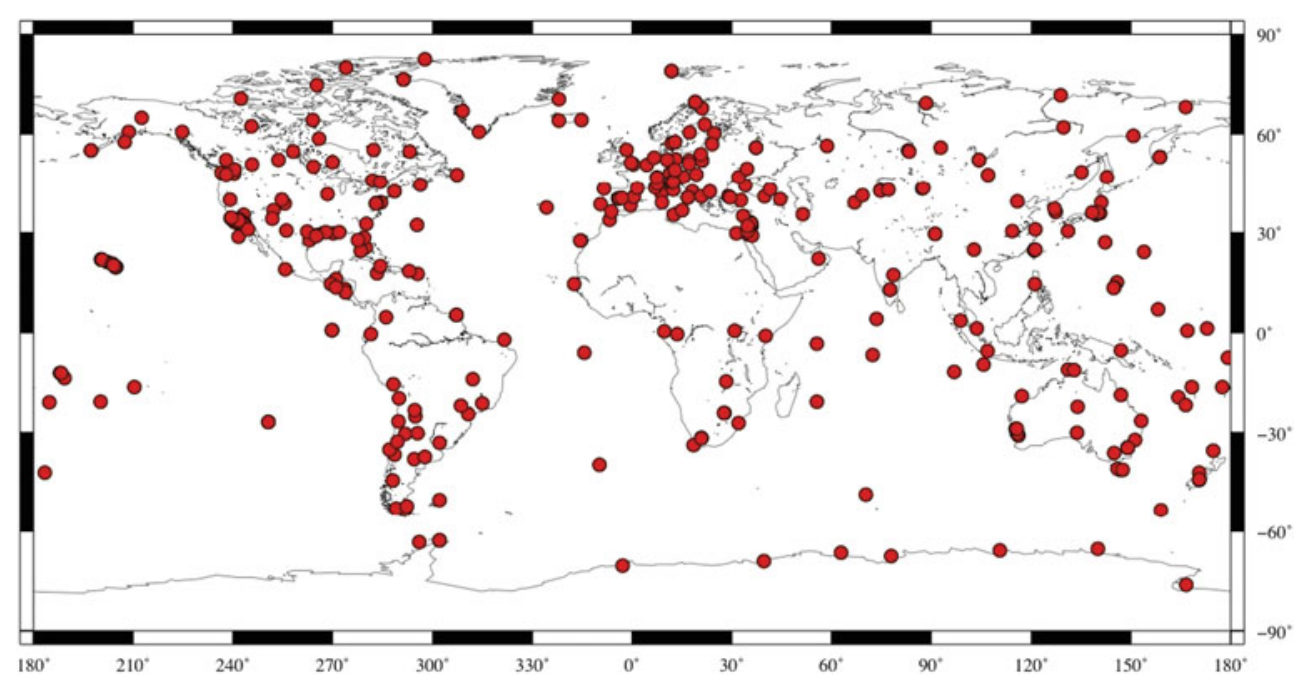

Fig. 1 Spatial distribution of the 344 IGS stations used in this analysis

\section{Results and Discussion}

\subsection{Comparison of the Weekly Loading Time Series Between Models}

Figure 2 shows an example of the detrended weekly loading time series for BRAZ (Brasilia, Brazil) and POTS (Potsdam, Germany) generated from our five CWS models. The detrended GPS time series is shown as black curve in the figure. Since the GPS time series include the ATML and NTOL effects, we also show the total weekly loading time series here (see the bottom panels for each station). For combination of the three loading effects, please refer to (Jiang et al. 2013) for detail. To address the difference between NCEP-R-1 and NCEP-R-2, the detrended loading time series from NCEP-R-1 is also shown as yellow curve. Note that of the five models listed in Table 1, only the loading time series from the GLDAS model exhibits a significant linear trend that is known to be artificial and should be removed (van Dam et al. 2001). For the MERRA and NCEP datasets, the linear trend is very small for most of the stations and can be neglected.

From Fig. 2 we observe that predicted heights from GLDAS and MERRA models track the trend of the GPS height time series better as compared with the two NCEP models, of which the NCEP-R-1 sometimes over estimates station's vertical displacement, while the NCEP-R-2 could only yield very small surface displacement. For the same spatial resolution, we observe that the temporal resolution differences, i.e. three-hourly versus monthly GLDAS, are only slightly different at the weekly samples shown here.
Thus, when comparing the models to one another, we will plot the results from the higher temporal resolution data sets GLDAS-B and MERRA-B hereafter. If we look at the difference among CWS models at the daily sampling, however, there would be bigger difference between different temporal resolution products.

From Fig. 2 we also notice that after considering the ATML and NTOL effects, the fitting between each CWS model and the weekly GPS height exhibits some difference, in particular for station POTS. Both the phase and amplitude of the CWS model become more closer with the applied GPS height. This result indicates that ATML and NTOL would have some impact on the performance of CWS modeling in correcting the GPS height time series.

An analysis of the two stations in Fig. 2 does not allow us to determine whether the GLDAS or MERRA model is better. The left panels of Fig. 3 show the standard deviation (STD) of the weekly loading time series for the 344 stations derived from GLDAS-B, MERRA-B and NCEP-R-2 model. In general, we can observe that the MERRA model yields a slightly bigger scatter than the GLDAS model across the continents, in particular for the stations above the latitude of 60.5 degree. The lower scatter in the GLDAS data at high latitudes is because we removed the SWE value in these regions when modeling the displacement from GLDAS. Quite different from the MERRA and GLDAS model, the NCEP-R-2 model yields very small STD value at most of places around the globe, while the STD of the NCEP-R-1 model is very large, especially for the central North America and Eurasia. Since our results on the NCEP-R-1 model is quite similar as that from (Jiang et al. 2013), we only show the results from the NCEP-R-2 model only hereafter. The 

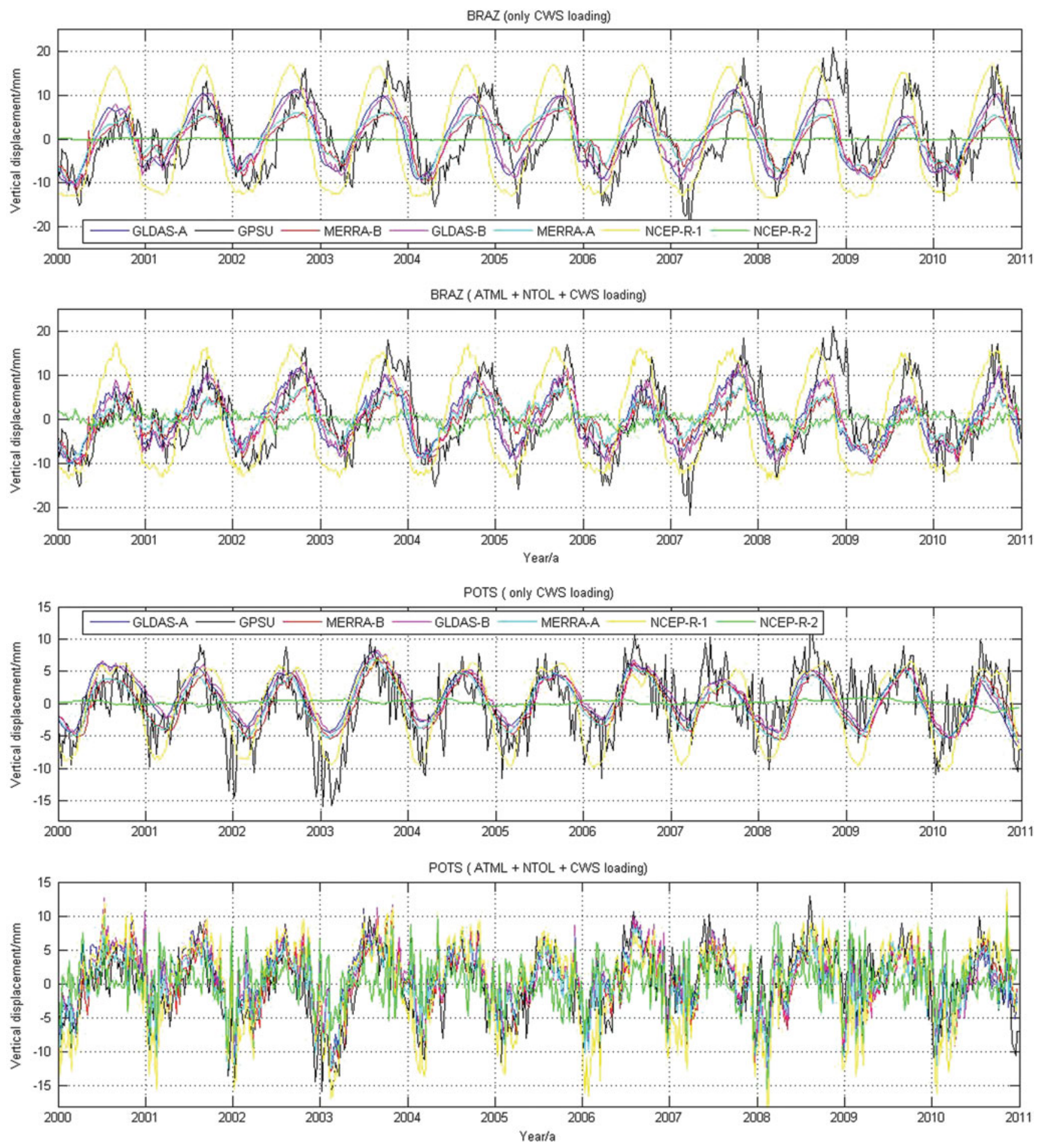

Fig. 2 Weekly vertical displacement of station BRAZ and POTS generated from different CWS models. Unit of the displacement is in mm

right panels of Fig. 3 show the correlations for GLDASB, MERRA-B and NCEP-R-2 with GLDAS-A. We can see that GLDAS-B has the largest correlation with GLDAS-A. However, MERRA-B and NCEP-R-2 do not correlate well with the GLDAS-A. This is particularly true for coastal and ocean areas.

\subsection{Comparison Between Loading and GPS Height Time Series}

To evaluate the quality of the CWS induced weekly vertical loading displacement, we calculate the Weighted Root Mean Square (WRMS) reduction of the GPS height time 

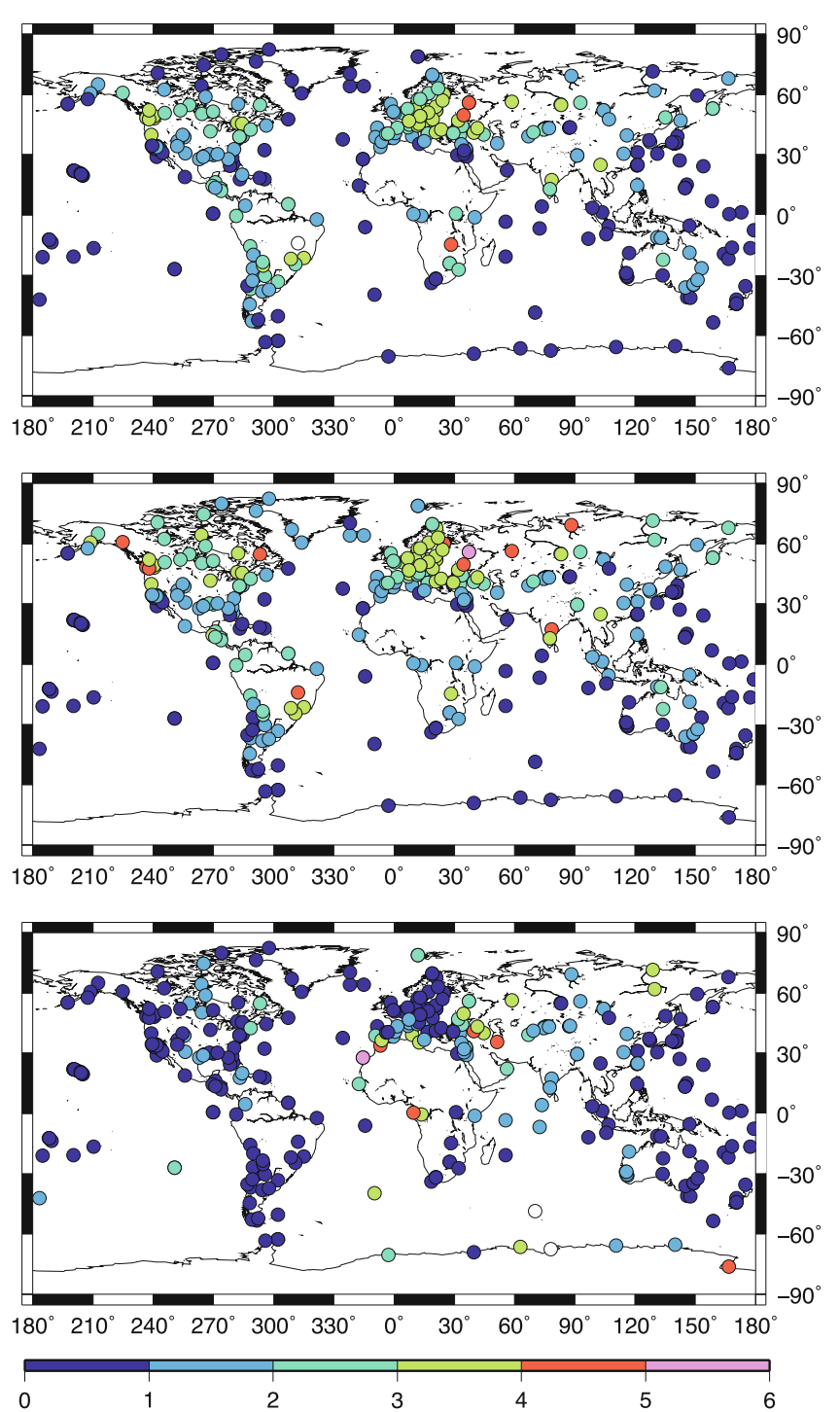

Fig. 3 Spatial distribution of the STD different CWS models (left) and their correlation with the reference model GLDAS-A (right). From top to bottom are GLDAS-B, MERRA-B and NCEP-R-2. Unit of the STD

series using the CWS models (Jiang et al. 2013) and the correlation coefficients between each CWS model and the GPS height. Some statistics of the WRMS and correlation results are shown in Table 2. The left panels of Fig. 4 show the WRMS results for GLDAS-B, MERRA-B and the NCEP-R-2 model. The reddish colors in the panels on the left hand side of the figure indicate that the station's WRMS was reduced when the model was applied; bluish colors indicate the WRMS of the heights increased. Black dots indicate that a station's WRMS increase exceeds the lower limit of the scale. The right panels of Fig. 4 illustrate the correlation of the models with the GPS height time series. The higher the correlation and WRMS reduction, the better the model is in correcting the GPS height for CWS effects.
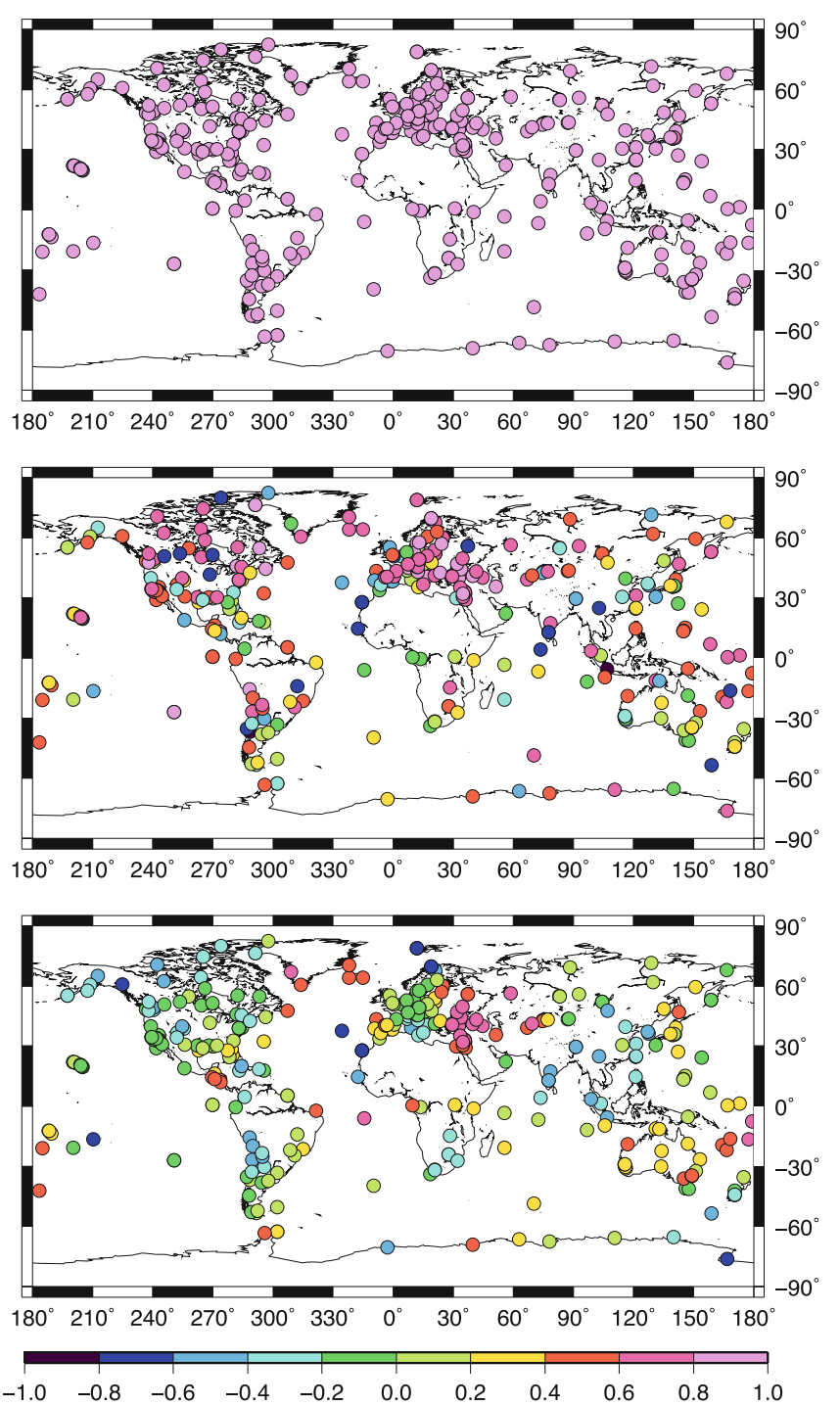

is in $\mathrm{mm}$. The white dots in the figure indicate that the STD value for the station is larger than the maximum value on the scale

From Fig. 4 and Table 2, we observe that the MERRA product has slightly higher correlations with GPS heights than the GLDAS model. More than 40 and $33 \%$ of the stations have correlations with the GPS heights larger than +0.5 for the MERRA-B and GLDAS-B models respectively. Those stations with stronger correlations are found mainly in central North America and Eurasia. The NCEP-R-2 model, however, has a very poor correlation with the weekly GPS height.

As for the WRMS reduction, MERRA-B and GLDASB reduce the scatter on 88 and $82 \%$ of the weekly GPS height respectively. The stations with the largest reductions in scatter (on the order of 10\%) are mostly in North America and Europe. Compared to GLDAS-B, MERRA-B improves the WRMS of the IGS stations to a greater extent in 

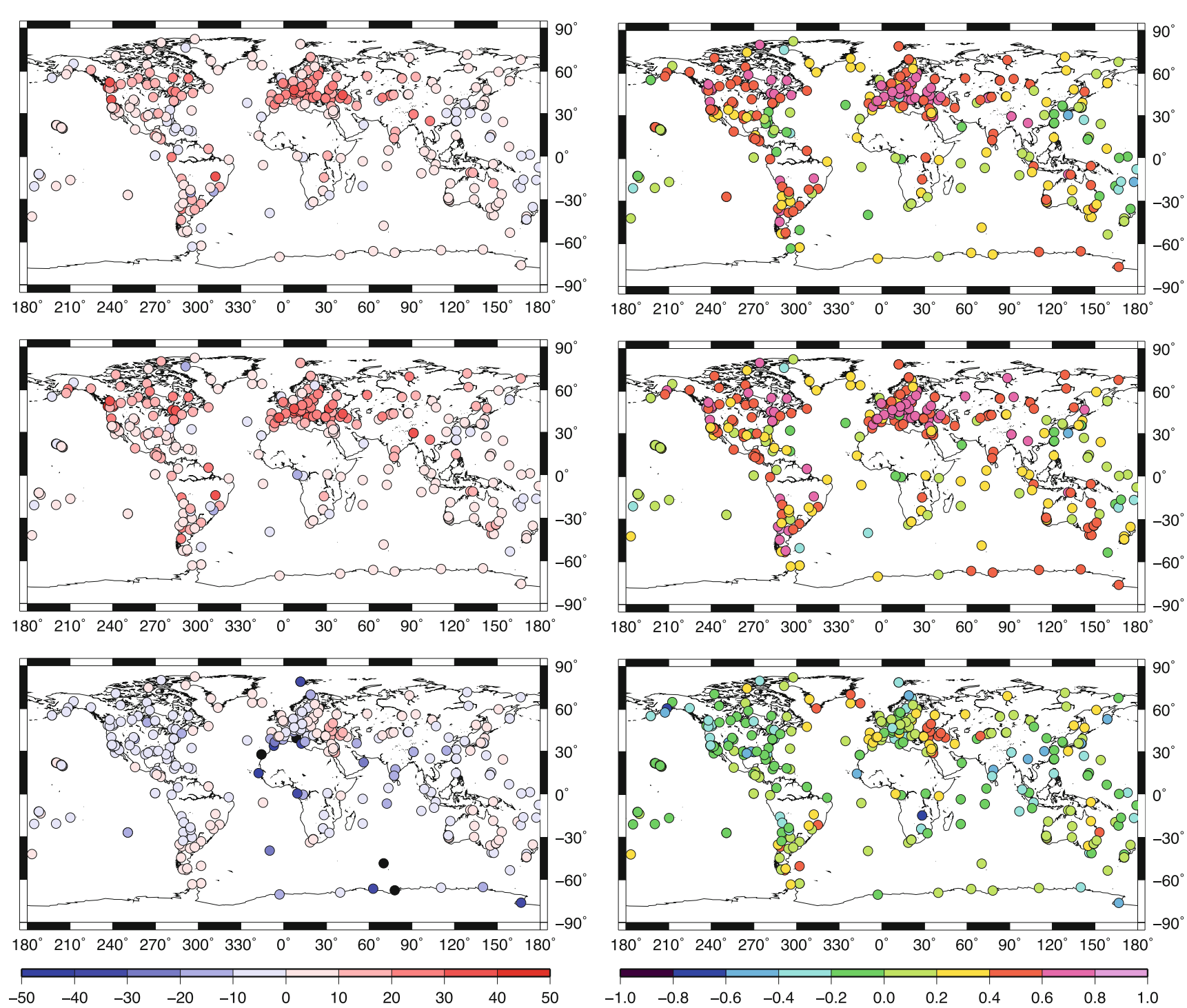

Fig. 4 Spatial distribution of the WRMS reduction rate using different CWS loading corrections (left) and their correlation with GPS height (right). From top to bottom are GLDAS-B, MERRA-B and NCEP-R-2.

The black dots in the figure indicate that the WRMS reduction for the station is smaller than the minimum value on the scale. Unit of the WRMS reduction is in \%

Table 2 Statistics of the correlation coefficients and the WRMS from the 5 CWS models

\begin{tabular}{lllll}
\hline & $\begin{array}{l}\text { Percentage of stations whose } \\
\text { correlation with GPS is } \\
\text { higher than +0.5 before } \\
\text { considering ATML and } \\
\text { NTOL effects }(\%)\end{array}$ & $\begin{array}{l}\text { Percentage of stations whose } \\
\text { correlation with GPS is } \\
\text { higher than +0.5 after } \\
\text { considering ATML and } \\
\text { NTOL effects }(\%)\end{array}$ & $\begin{array}{l}\text { Percentage of stations with } \\
\text { WRMS reduced before } \\
\text { considering ATML and } \\
\text { NTOL effects }(\%)\end{array}$ & $\begin{array}{l}\text { Percentage of stations with } \\
\text { WRMS reduced after } \\
\text { considering ATML and } \\
\text { NTOL effects }(\%)\end{array}$ \\
\hline GLDAS-A & 30 & 51 & 78 & 88 \\
\hline GLDAS-B & 34 & 53 & 82 & 89 \\
\hline MERRA-A & 35.6 & 52 & 80 & 88 \\
\hline NERRA-B & 41.8 & 55 & 88 & 63 \\
\hline
\end{tabular}

South America, southeast Asia, and those close to the Pacific Ocean. Note that although the SWE data above the latitude of 60.5 degree is included when modeling the displacement using the MERRA-B model, it has no advantage over the
GLDAS-B model in reducing the WRMS of stations in Greenland.

MERRA-A and GLDAS-A also reduce the WRMS to a reasonable extent, although the WRMS reduction is not 

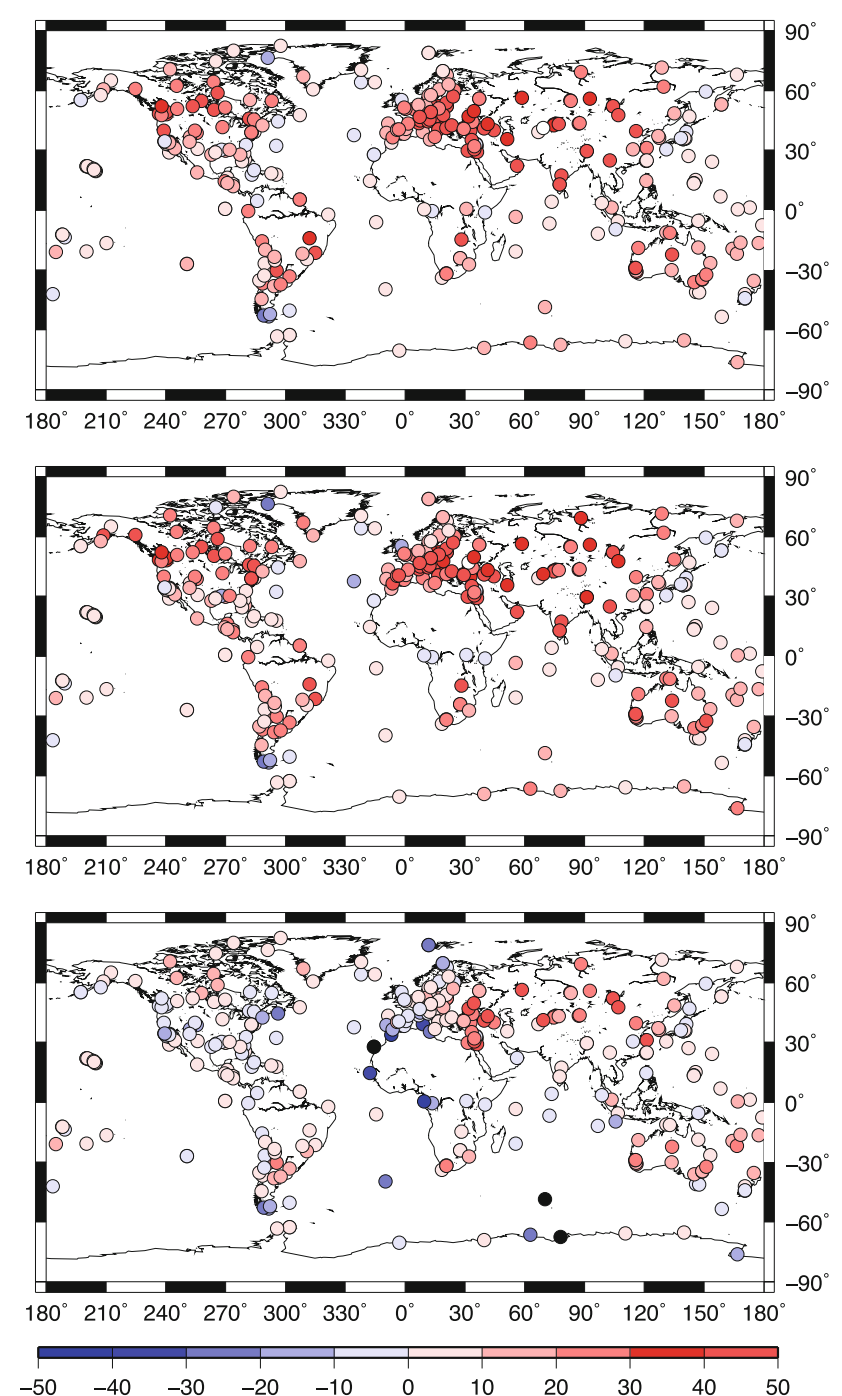

Fig. 5 Spatial distribution of the WRMS reduction rate using different CWS loading corrections (left) and their correlation with GPS height (right) after removing the ATML and NTOL effects. From top to bottom are GLDAS-B, MERRA-B and NCEP-R-2. The black dots in

as good as for the higher temporal resolution products. Compared with GLDAS and MERRA model, however, the NCEP-R-2 model could only reduce $36 \%$ of the stations' WRMS, and the biggest improvement is found mainly in Europe. This is even much worse than the NCEP-R-1 model (Jiang et al. 2013). Therefore, we conclude that the CWS data from both the GLDAS and MERRA products could be used for correcting the GPS height to some extent, among which the higher spatial resolution product MERRA does slightly better performance. This mainly due to the scientific and technical improvement of the MERRA-Land product itself. Under the same spatial resolution, the higher temporal resolution model could also improve its correlation with the weekly GPS height by about $2-6 \%$, together with its performance in reducing the WRMS. Better fitting results
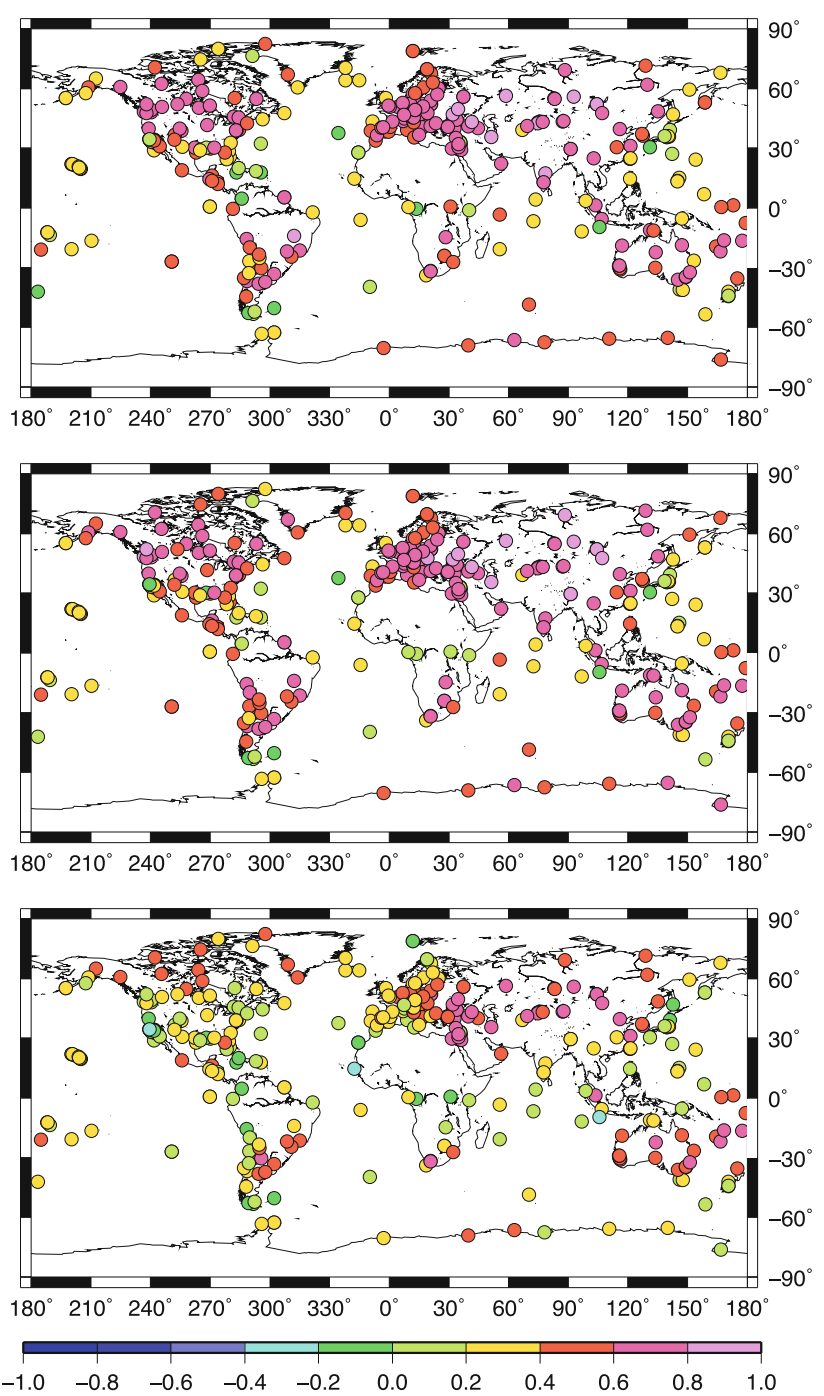

the figure indicate that the WRMS reduction for the station is smaller than the minimum value on the scale, while the white dots means the WRMS reduction is larger than the maximum value. Unit of the WRMS reduction is in \%

would be expected when comparing the three-hourly or hourly CWS model with higher temporal resolution GPS height time series. Similar as the NCEP-R-1 model, the NCEP-R-2 model may also not be suitable in this kind of application.

Since ATML and NTOL may affect the comparison results (see Fig. 2), we recalculate the WRMS and the correlation coefficients after removing the ATML and the NTOL effects from the weekly GPS height. The left panels Fig. 5 show the WRMS results for GLDAS-B, MERRA-B and the NCEP-R-2 model, while the right panels show their correlation with the ATML and NTOL-removed GPS height. We also show some of the statistics of each CWS model in Table 2 for the ATML and NTOL removed results. We find that MERRA-B performs slightly better than GLDAS-B 
in correcting the weekly GPS height, while MERRA-A and GLDAS-A rank the third and fourth respectively. The NCEP-R-2 model could also reduce the WRMS of $63 \%$ of the stations after removing the ATML and NTOL effects, especially for East Europe and central Asia.

Compared Fig. 5 with Fig. 4, we confirm that ATML and NTOL have a significant impact on the comparison between CWS model and the GPS height generally. After removing the ATML and NTOL effects, the correlation between each CWS model and the weekly GPS height improved by about 13-20\% at most stations, and the WRMS reduction for most stations also improved by at least $10 \%$, in particular for those located along coast or in the oceans. Hence, to make a more realistic comparison between CWS loading and GPS time series, the effects of ATML and NTOL would better be removed first.

\section{Conclusions}

We compare the weekly vertical surface displacements from five CWS models. We inter-compare the models with each other and then compare all the models with a set of weekly GPS height time series. We find that overall the higher spatial resolution MERRA products are better at correcting the weekly GPS height than the GLDAS products. This result is mainly due to the scientific and technical improvement of the MERRA-Land data itself. Under the same spatial resolution, the CWS models with higher temporal resolution performs slightly better than that with a coarser resolution by about 2-6\%. We also confirm that removing the ATML and NTOL effects from the weekly GPS height would improve the correlation between CWS model and the GPS height by about $13-20 \%$ at most stations, and the WRMS reduction could also improve by at least $10 \%$, especially for coastal and island stations.

We find that the one-hourly soil moisture and snow mass data from the improved MERRA-Land datasets is the most appropriate product for modeling vertical surface displacement by CWS variations. The three-hourly GLDAS data also does well in reducing the WRMS in the GPS height. Considering that the GLDAS products have a higher latency than the MERRA products, MERRA would be a better choice for modeling CWS surface displacements. Further work is still required to determine the reliability and precision of the CWS products. We confirm that the NCEP-R-2 data is also insufficient for applying this correction. Note that all these results are obtained using GPS coordinate time series obtained without considering the impacts of atmospheric tides and higher-order ionospheric delay, we claim that this is one of the limitations of this research. After the 2nd IGS reprocessing has been done, different conclusions may be drawn.
Until now, the GLDAS also provides 0.25 degree product from February 2, 2000 to the present. Due to this model's higher spatial resolution, better results would be expected if we use this type of product to predict surface displacement. Also, the recent reprocessed Jet Propulsion Laboratory (JPL) daily GPS coordinate time series with seasonal signal restored is available now. ${ }^{11}$ The vertical loading displacement induced from the 3-hourly GLDAS and 1-hourly MERRA products should perform much better at correcting the daily GPS height time series than the most frequently used monthly CWS products.

Acknowledgements We thank the NASA and NOAA for making the MERRA-LAND, GLDAS and NCEP data freely available. Figures are plotted with the GMT and MATLAB software.

\section{References}

Blewitt G (2003) Self-consistency in reference frames, geocenter definition, and surface loading of the solid Earth. J Geophys Res 108(B2):2103. doi: 10.1029/2002JB002082

Chen Q, van Dam T, Sneeuw N, Collilieux X, Weigelt M, Rebischung $P$ (2013) Singular spectrum analysis for modeling seasonal signals from GPS time series. J Geodyn. doi:10.1016/j.jog.2013.05.005

Clarke P, Lavalle D, Blewitt G, van Dam T, Wahr J (2005) Effect of gravitational consistency and mass conservation on seasonal surface mass loading models. Geophys Res Lett 32(L08306):1-5. doi:10. 1029/2005GL022441

van Dam T, Wahr J (1987) Displacements of the Earth's surface due to atmospheric loading: effects on gravity and baseline measurements. J Geophys Res 92(B2):1281-1286. doi:10.1029/JB092iB02p01281

van Dam T, Wahr J, Milly PCD, Shmakin AB, Blewitt G, Lavallée D, Larson KM (2001) Crustal displacements due to continental water loading. Geophys Res Lett 28(4):651-654. doi:10.1029/ 2000GL012120

van Dam T, Wahr J, Lavallée D (2007) A comparison of annual vertical crustal displacements from GPS and gravity recovery and climate experiment (GRACE) over Europe. J Geophys Res 112(B3):B03,404. doi:10.1029/2006JB004335

Dong D, Dickey JO, Chao Y, Cheng MK (1997) Geocenter variations caused by atmosphere, ocean and surface ground water. Geophys Res Lett 24(15):1867-1870. doi:10.1029/97GL01849

Dow JM, Neilan R, Rizos C (2009) The International GNSS Service in a changing landscape of global navigation satellite systems. J Geod 83:191-198. doi:10.1007/s00190-008-0300-3

Farrell WE (1972) Deformation of the Earth by surface loads. Rev Geophys 10(3):761-797. doi:10.1029/RG010i003p00761

Fritsche M, Döll P, Dietrich R (2012) Global-scale validation of model-based load deformation of the Earth's crust from continental watermass and atmospheric pressure variations using GPS. J Geodyn 59-60(0):133-142. doi:10.1016/j.jog.2011.04.001

Jiang W, Li Z, van Dam T, Ding W (2013) Comparative analysis of different environmental loading methods and their impacts on the GPS height time series. J Geod 1-17. doi:10.1007/s00190-0130642-3

Kalnay E, Kanamitsu M, Kistler R, Collins W, Deaven D, Gandin L, Iredell M, Saha S, White G, Woollen J, Zhu Y, Chelliah M, Ebisuzaki W, Higgins W, Janowiak J, Mo K, Ropelewski C, Wang J, Leetmaa

${ }^{11} \mathrm{http}: / /$ sideshow.jpl.nasa.gov/post/series.html. 
A, Reynolds R, Jenne R, Joseph D (1996) The NCEP/NCAR 40year reanalysis project. Bull Am Meteorol Soc 77(3):437-471. doi:10.1175/1520-0477(1996)077<0437:TNYRP>2.0.CO;2

Kanamitsu M, Ebisuzaki W, Woollen J, Yang Sk, Hnilo JJ, Fiorino M, Potter GL (2002) Ncep-doe amip-ii reanalysis (r-2). Bull Am Meteorol Soc 83(83):1631-1643. doi:http://dx.doi.org/10.1175/BAMS83-11-1631

Rebischung P, Griffiths P, Ray J, Schmid J, Collilieux X, Garayt B (2012) IGS08:the IGS realization of ITRF2008. GPS Solutions 16:483-494. doi:10.1007/s10291-011-0248-2

Reichle RH (2012) The MERRA-Land Data Product. GMAO Office Note No. 3 (version 1.2), 38 pp

Reichle RH, Koster RD, De Lannoy GJM, Forman BA, Liu Q, Mahanama SPP, Tour A (2011) Assessment and enhancement of
MERRA Land surface hydrology estimates. J Climate 24(24):63226338. doi:10.1175/JCLI-D-10-05033.1

Rui H (2011) README document for global land data assimilation system version 1 (GLDAS-1) products. http://disc.sci.gsfc.nasa.gov/ services/grads-gds/gldas, GSFC online document, $34 \mathrm{pp}$

Tregoning P, Watson C, Ramillien G, McQueen H, Zhang J (2009) Detecting hydrologic deformation using GRACE and GPS. Geophys Res Lett 36(15):L15,401. doi:10.1029/2009GL038718

Wessel P, Smith WH (2013) The generic mapping tools technical reference and cookbook (version 4.5.11). https://www.soest.hawaii. edu/gmt/gmt/pdf/GMT_Docs.pdf, GMT online document, $250 \mathrm{pp}$ 